\section{Journal of Anatolian Environmental and Animal Sciences \\ (Anadolu Çevre ve Hayvancılık Bilimleri Dergisi) \\ Doi: https://doi.org/10.35229/jaes.635941}

\title{
Artvin İli Tatlı Su Ekosistem Sedimentlerin'de Ağır Metallerin Çevresel Ekolojik Risk Etkilerinin Alansal ve Zamansal Değerlendirilmesi
}

\author{
Koray ÖZŞEKER \\ "Karadeniz Teknik Üniversitesi, Deniz Bilimleri ve Teknolojisi Enstitüsü, Trabzon, TÜRKIYYE \\ (iD): https://orcid.org/0000-0002-7044-1843
}

Atıf yapmak için: Özşeker, K. (2019). Artvin İli Tatlı Su Ekosistem Sedimentlerin'de Ağır Metallerin Çevresel Ekolojik Risk Etkilerinin Alansal ve Zamansal Değerlendirilmesi. Anadolu Çev. ve Hay. Dergisi, 4(3), 551-559.

How to cite: Özşeker, K. (2019). Spatial and Temporal Assessment of Environmental Ecological Risk Effects of Heavy Metals in Freshwater EcosystemSediments in Artvin Province. Anatolian Env. and Anim. Sciences, 4(3), 551-559.

Öz: Bu çalışmada, doğal ve antropojenik kaynaklı metal kirliliğinin ekolojik risk durumu Artvin İlinde bulunan tatlı su ekosistem sedimentlerinde fizikokimyasal parametreler ile birlikte alansal ve zamansal olarak incelenmiştir. Tatlı su ekosistemleri bölgede bulunan baraj gölleri ve bu gölleri besleyen dereler olmak üzere iki alt kategoride irdelenmiştir. Bu kapsamda araştırma her bir baraj gölü için 4'er istasyon ve baraj göllerini besleyen her bir dere için 3'er istasyon olmak üzere 21 farklı istasyon belirlenerek yapılmıştır. Örnekler 2-75 m derinlik aralığından elde edilmiştir. Örneklemeler ilkbahar, sonbahar, kış ve yaz olmak üzere dört farklı iklim koşulunda Haziran 2015 ve Eylül 2016 tarihleri arasında mevsimsel olarak yürütülmüştür. Bakır $(\mathrm{Cu})$ ve Kurşun $(\mathrm{Pb})$ araştırılacak elementler olarak seçilmiştir. Ağır metal analizleri ACME analitik kimya laboratuarında ICP-MS yöntemi ile gerçekleștirilmiştir. En yüksek ortalama metal değerleri sonbahar mevsiminde göl ekosistemleri içerisinde Borçka Baraj Gölü'nde $(\mathrm{Cu}=361,9$ ppm, $\mathrm{Pb}=176,8$ ppm), dere ekosistemleri içerisinde ise Murgul Deresi'nde( $\mathrm{Cu}=$ $801,3 \mathrm{ppm}, \mathrm{Pb}=192,7 \mathrm{ppm}$ ) olarak tespit edilmiştir. Bölgedeki kirlilik boyutunun ortaya konulması amaciyla sediment zenginleşme faktörü (SEF), kirlilik yük indeksi (PLI), jeoakümülasyon indeksi ( $\mathrm{I}_{\mathrm{GEO}}$ ), toplam ekolojik risk indeksi (RI) ve sediment kalite rehberi (SGV) yöntemleri kullanılmıştır. $\mathrm{Bu}$ çalışmanın sonuçlarına dayanarak, $\mathrm{Cu}$ ve $\mathrm{Pb}$ elementlerinin Artvin ili tatlı su ekosistemleri için toksik etki gösterebileceği ve bu ekosistemlerin metal kirliliği açısından orta risk sınıfında yer aldığı ortaya konulmuştur.

Anahtar sözcükler: Ekosistem, Tatlısu, kirlilik, metal

\section{Spatial and Temporal Assessment of Environmental Ecological Risk Effects of Heavy Metals in Freshwater EcosystemSediments in Artvin Province}

\begin{abstract}
In this study, the ecological risk status of natural and anthropogenic origin metal pollution was investigated spatially and temporally together with physicochemical parameters in the freshwater ecosystem sediments of Artvin province. Freshwater ecosystems are examined in two sub-categories as dam lakes and streams feeding these lakes. In this context, the survey was conducted by identifying 21 different stations, including 4 stations each for each dam lake and 3 stations each for each stream feeding the dam lakes. Samples were obtained from a depth range of 2-75 m. The samples were seasonally conducted between June 2015 and September 2016 under four different climatic conditions: spring, autumn, winter and summer. The highest average metal values were observed in Borçka Dam Lake which is the lake ecosystems $(\mathrm{Cu}=361.9 \mathrm{ppm}, \mathrm{Pb}=176.8 \mathrm{ppm})$ and Murgul Stream which is the river ecosystems $(\mathrm{Cu}=801.3 \mathrm{ppm}, \mathrm{Pb}=192.7 \mathrm{ppm})$ in the autumn season. Sediment enrichment factor (SEF), pollution load index (PLI), geoaccumulation index (IGEO), total ecological risk index (RI) and sediment quality guide (SGV) methods were used to determine the pollution size in the region. Based on the results of this study, it was concluded that $\mathrm{Cu}$ and $\mathrm{Pb}$ elements can be toxic effects for freshwater ecosystems in Artvin province and these ecosystems should be evaluated in the medium risk class in terms of metal pollution.
\end{abstract}




\section{GİRIŞ}

Artvin ili 7436 km'lik bir alan ile küçük bir bölgeye sahip olmasına rağmen gerek topoğrafyasının dik ve engebeli olması gerekse de özellikle sahil kesimi başta olmak üzere, yoğun yağış alması hasebiyle yılın belli dönemlerinde önemli taşkınlara maruz kalmaktadır (Anonim, 2015).Önemli ölçüde görülen taşkınlar bölgede yüksek erozyona sebebiyet vermektedir.

Artvin il sınırları içerisinde aktif olarak 45 adet ana dere olmakla birlikte yüzlerce kuru dere bulunmaktadır. Maden yataklarınca zengin olan Artvin ilin 'de erozyona bağlı olarak sucul ekosistemlere yüklü miktarlarda ağır metal girişi söz konusudur (Anonim, 2010). Maden Teknik Arama (MTA) ve özel kuruluşların bugüne kadar Artvin İli sınırları içinde yapmış oldukları çeşitli jeoloji ve madencilik çalışmaları sonucunda kayda değer 44 adet bakır-kurşunçinko, 1 adet demir, 17adet manganez, 5 adet bakır-molibden ve 5 adet altın yatağ 1 olmak üzere toplam 72 adet metalik maden yatağ 1 olduğunu ortaya konulmuştur (Anonim, 2005). Ayrıca, gelişen teknoloji, nüfusun hızla artması, küresel iklim değişikliği, evsel, endüstriyel ve tarımsal kirlilik kaynakları tatlı su ekosistemleri üzerinde büyük bir baskı oluşturmaktadır (Taş, 2011). Artvin'deki hemen hemen bütün çay ve dereler Çoruh'un kollarını oluşturmaktadır. Toplam uzunluğu $431 \mathrm{~km}$ olan Çoruh Nehri'nin Artvin il sınırları içerisindeki uzunluğu 150 kilometredir. Çoruh Nehri'nin 150 km boyunca aktığı Artvin il sınırları içerisinde günümüz itibariyle Deriner, Borçka ve Muratlı olmak üzere 3 baraj gölü bulunmaktadır.

Eğimi \%5 olan Çoruh'un debisi Mayıs ayında 569 $\mathrm{m}^{3} / \mathrm{sn}$ ile zirveye çıkar. Y1l boyunca en düşük debisi ise 53,09 $\mathrm{m}^{3} / \mathrm{sn}$ 'dir. Çoruh Nehri'nin yılda getirdiği sediment (çökelti) ise 5,8 milyon $\mathrm{m}^{3}$ 'tür. $\mathrm{Bu}$ nedenle nehir havzası Türkiye'de erozyona en fazla maruz kalan bölgeler arasında gösterilir (Anonim, 2005).

Sucul ortamlarda ağır metal kirliliğinin en önemli kaynaklarından bir tanesi de karasal kaynaklı erozyondur. $\mathrm{Bu}$ şekilde metal bileşikleri su kolonuna girmekte ve çökelme sonrasında sediment tabakasında birikmektedirler.
Sedimentlerde biriken değişik kökene sahip bu kirleticiler, fiziksel, kimyasal ve biyolojik süreçlerle çökelme sonrası tekrar su kolonuna geçiş yapabilir. Böylece sedimentler sulu ortamlardaki çevre kirleticileri için bir kaynak özelliğindedirler (Förstner, 1989). Dolayısıyla su ortamlarında var olan kirliliğin belirlenmesinde sediment analizlerinin rolü büyüktür.

$\mathrm{Bu}$ çalışma kapsamında sediment analizlerine dayalı ağır metal kirliliğinin mevcut durumunu ekosistem yaklaşımlı tespit etmek amacıyla Sediment Zenginleşme Faktörü (SEF), Kirlilik Yük İndeksi (PLI), Jeoakümülasyon İndeksi ( $\mathrm{I}_{\mathrm{GEO}}$ ) ve Ekolojik Risk İndeksi (ER) yöntemleri kullanılmıştır (Abraham \& Parker, 2008; Çevik vd., 2009; Swarnalatha vd., 2013a; Özşeker, 2019). Ayrıca, sediment tabakasında birikim gösteren metal konsantrayonları, Sediment Kalite Rehberi (SOQ), Dünya Ortalama Şeyl Değerleri (WASV), Kita Kabuğu Değerleri (CCV) ve Toksisite Referans Değerleri (TRV) gibi dünya literatüründe kabul görmüş referans değerleri ile irdelenerek bölgenin alansal ve zamansal mevcut durumu ortaya konulması amaçlanmıştır. (Kurupadam vd., 2006; Swarnalatha vd., 2013b).

\section{MATERYAL ve METOT}

Örnekleme Sahası: Bu çalışma, Artvin ili tatlı su ekosistemlerini bünyesine alan ağır metal kirliliği araştırmasıdır. Bu kapsamda, Borçka, Muratlı ve Deriner Baraj Gölleri ile bu gölleri besleyen ve Çoruh Nehri'nin kolları durumunda olan Murgul, Deviskel ve Ardanuç Dereleri olmak üzere altı farklı sahada gerçekleştirilmiştir (Şekil 1).

Araştırma her bir baraj gölü için 4'er istasyon ve baraj göllerini besleyen her bir dere için 3'er istasyon olmak üzere 21 farklı istasyon belirlenerek yapılmıştır (Tablo 1). Örnekleme çalışmaları; Haziran 2015 ve Eylül 2016 tarihleri arasında mevsimsel olarak yürütülmüştür.

Tablo 1. Çalışma alanına ait koordinatlar.

\begin{tabular}{|c|c|c|c|c|c|c|c|c|c|}
\hline \multicolumn{10}{|c|}{ Baraj Gölleri } \\
\hline \multirow{2}{*}{ İst. } & \multicolumn{3}{|c|}{ Boçka } & \multicolumn{3}{|c|}{ Muratlı } & \multicolumn{3}{|c|}{ Deriner } \\
\hline & Enlem & Boylam & Derinlik (m) & Enlem & Boylam & Derinlik (m) & Enlem & Boylam & Derinlik (m) \\
\hline 1 & $41^{\circ} 20,88^{\prime}$ & $41^{\circ} 41,34^{\prime}$ & 72 & $41^{\circ} 27,80^{\prime}$ & $41^{\circ} 42,81^{\prime}$ & 35 & $41^{\circ} 10,06^{\prime}$ & $41^{\circ} 52,70^{\prime}$ & 75 \\
\hline 2 & $41^{\circ} 19,62^{\prime}$ & $41^{\circ} 42,70^{\prime}$ & 65 & $41^{\circ} 26,84^{\prime}$ & $41^{\circ} 41,93^{\prime}$ & 55 & $41^{\circ} 09,50^{\prime}$ & $41^{\circ} 53,67^{\prime}$ & 65 \\
\hline 3 & $41^{\circ} 17,08^{\prime}$ & $41^{\circ} 45,40^{\prime}$ & 45 & $41^{\circ} 25,89^{\prime}$ & $41^{\circ} 42,18^{\prime}$ & 50 & $41^{\circ} 08,39^{\prime}$ & $41^{\circ} 53,74^{\prime}$ & 60 \\
\hline 4 & $41^{\circ} 14,41^{\prime}$ & $41^{\circ} 47,03^{\prime}$ & 32 & $41^{\circ} 24,60^{\prime}$ & $41^{\circ} 41,86^{\prime}$ & 65 & $41^{\circ} 07,18^{\prime}$ & $41^{\circ} 52,41^{\prime}$ & 50 \\
\hline \multicolumn{10}{|c|}{ Dereler } \\
\hline \multirow{2}{*}{ İst. } & \multicolumn{3}{|c|}{ Murgul } & \multicolumn{3}{|c|}{ Deviskel } & \multicolumn{3}{|c|}{ Ardanuç } \\
\hline & Enlem & Boylam & Derinlik (m) & Enlem & Boylam & Derinlik (m) & Enlem & Boylam & Derinlik (m) \\
\hline 1 & $41^{\circ} 20,34^{\prime}$ & $41^{\circ} 40,56^{\prime}$ & 8 & $41^{\circ} 21,17^{\prime}$ & $41^{\circ} 40,43^{\prime}$ & 3 & $41^{\circ} 07,45^{\prime}$ & $42^{\circ} 03,69^{\prime}$ & 3 \\
\hline 2 & $41^{\circ} 18,30^{\prime}$ & $41^{\circ} 37,08^{\prime}$ & 7 & $41^{\circ} 21,93^{\prime}$ & $41^{\circ} 41,04^{\prime}$ & 6 & $41^{\circ} 07,95^{\prime}$ & $42^{\circ} 02,84^{\prime}$ & 7 \\
\hline 3 & $41^{\circ} 16,76^{\prime}$ & $41^{\circ} 33,97^{\prime}$ & 2 & $41^{\circ} 22,76^{\prime}$ & $41^{\circ} 41,11^{\prime}$ & 8 & $41^{\circ} 09,63^{\prime}$ & $41^{\circ} 58,33^{\prime}$ & 10 \\
\hline
\end{tabular}




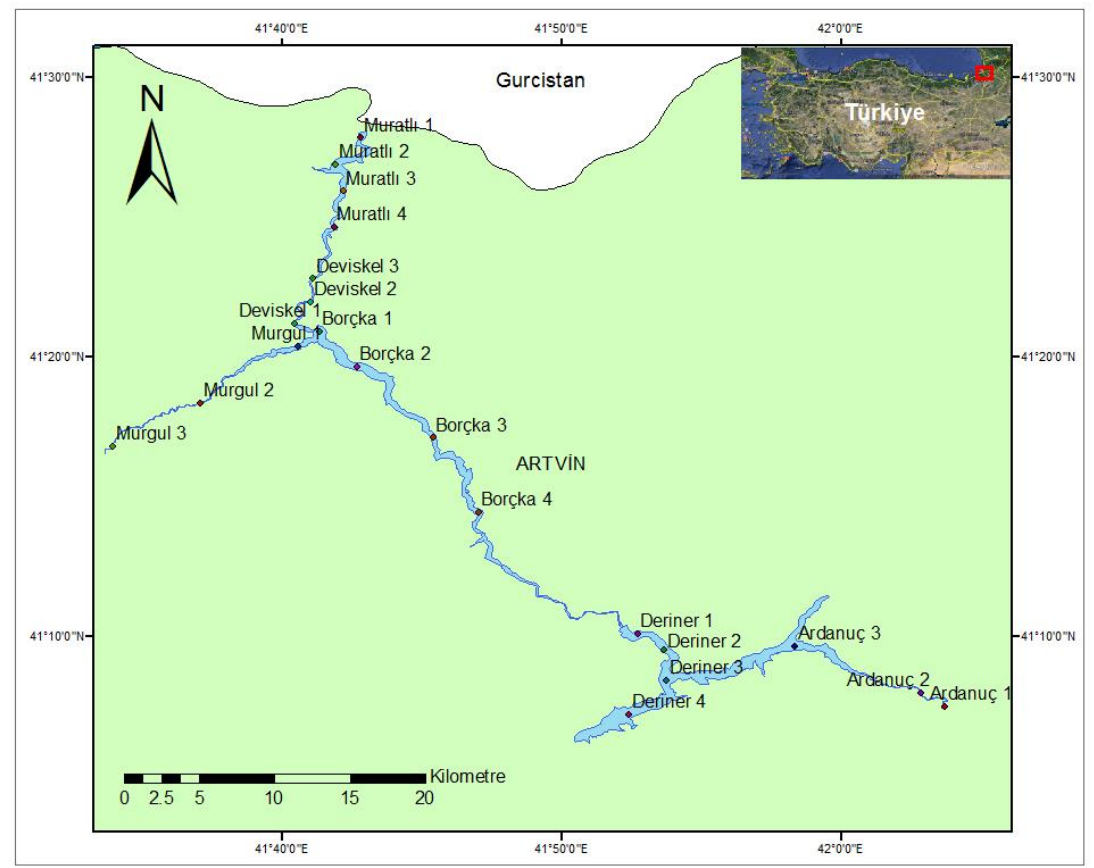

Şekil 1. Çalışma sahası.

Sediment örneklerinin alınmasında sediment kor örnekleyicisi (Wildco) kullanılmıştır. Çalışma esnasında bloğun bozulmamasına büyük önem gösterilmiştir. Örnekleme yapılan sediment bloğundan $(0-1 \mathrm{~cm})$ alınan örnekler derin dondurucuda $-18{ }^{\circ} \mathrm{C}$ de analiz aşamasına kadar bekletilmiştir. Göl ve dere sularının yüzey suyu sıcaklık, tuzluluk, çözünmüş oksijen ve $\mathrm{pH}$ gibi çevresel parametreleri su analiz seti Hach Lange HQ40D model ölçüm cihazı kullanılarak belirlenmiştir. Sediment tabakasının kil ve diğer boyuttaki malzeme fraksiyonlarını belirlemek amacıyla ıslak elek analiz yöntemi kullanılarak boyut analizleri yapılmıștır (Aytekin, 2004). Sedimentlerin yapısal özellikleri UNEP 1995'e göre belirlenmiştir. Bölgede bolca Bakır $(\mathrm{Cu})$ ve Kurşun $(\mathrm{Pb})$ maden yatakları mevcut olduğu için bu metaller araştırma için değerlendirilmiștir. Sediment örneklerinde, analiz edilecek iz elementler Dulski, (2001)'e göre hazırlanmıştır. Ağır metal analizleri ACME Analytical Laboraties Ltd. (Kanada) analitik kimya laboratuarında ICP-MS cihazı kullanılarak gerçekleştirilmiştir. ICP-MS tekniği ile İz elementlerde alt analiz limitleri; $\mathrm{Cu}$ ve $\mathrm{Pb} \quad 0,01 \quad \mathrm{ppm}$ olarak değerlendirilmiştir.

Sediment Kirliliğini ve Kalite Kriterlerini Belirleyen Metotlar: Sediment Zenginleşme faktörü (SEF), sedimentteki metalin antropojenik etkilerini değerlendirmek amacıyla kullanılmaktadır.

\section{$\mathrm{SEF}=($ Metal/Alüminyum) örnek / (Metal/ Alüminyum) kabuk}

Genellikle ağır metal çalışmalarında metallerin kaynaklarını belirlemek için $\mathrm{Al}$ ve $\mathrm{Fe}$ gibi konservatif elementler kullanılarak jeokimyasal normalizasyon yapılır. $\mathrm{Bu}$ çalışmada zenginleşme faktörünü hesaplarken normalleştirme elementi olarak Al kullanılmıştır. $0,5 \leq \mathrm{EF} \leq$
1,5 ise metal litojenik kaynaklı veya doğal ayrışma sonucu; $\mathrm{EF}>1,5$ ise metalin antropojenik kaynaklardan geldiği düşünülmektedir (Xiao vd., 2014).

Kirlilik yük indeksi (PLI), çevredeki metal kirliliğinin şiddetini değerlendiren etkili bir yöntemdir. Kirlilik yük indeksi tek bir alan için $\mathrm{n}$ sayıdaki metalin kontaminasyon faktör (CF) değerleri çarpımının karekökü olarak hesaplanır (Özşeker vd., 2014). Kontaminasyon faktörü ve buna bağlı kirlilik yük indeksi (PLI) aşağıdaki formüllere $(2,3)$ göre hesaplanır;

$\mathrm{CF}($ Kirlilik faktörü $)=$ Sediment metal değeri / Standart metal değeri

$\mathrm{PLI}=(\mathrm{CF} 1 \mathrm{xCF} 2 \mathrm{xCF} 3 \mathrm{x} \ldots \ldots \mathrm{xCFn})^{1 / \mathrm{n}}$

Yukarıda belirtilen formülün sonucuna göre, PLI $>1$ ise çalışılan alanda kirliliğin mevcut olduğu, eğer $\mathrm{PLI}<1$ ise kirliliğin mevcut olmadığı sonucuna varılır.

Sediment tabakasında ağır metal konsantrasyonu üzerinde antropojenik etkinin derecesini belirlemek için kullanılan yaygın yöntemlerden biride Jeoakümülasyon indeksidir. Bu yöntem Muller (1981) tarafindan ortaya konulmuştur. Bu yöntemin esası aşağıda belirtilen formüle (4) ve sinıflandırma kriterlerine (Tablo 2) göre değerlendirilmektedir. Çalışma alanından elde edilen örneklerin değerlendirilmesi aşağıdaki formül ve sinıflandırılmaya göre hesaplanacak ve antropojenik etki derecesi ortaya konulacaktır.

$$
\mathrm{I}_{\mathrm{GEO}}=\log _{2}[\mathrm{Cn} /(1.5 \times \mathrm{Bn})]
$$

Yukarıda verilen formülde $\mathrm{Cn}$ sediment tabakasında ölçülen element konsantrasyonu, Bn ise literatürde kabul görmüş referans element jeokimyasal konsantrasyonu olarak tanımlanmaktadır. 
Tablo 2. IGEo kirlilik yoğunluğu sinıflandırılması.

\begin{tabular}{lll}
\hline $\mathbf{I}_{\mathrm{GEO}}$ & $\mathbf{I}_{\mathrm{GEO}}$ Sinıflandırma & Kirlilik Yoğunluğu \\
\hline $\mathrm{I}_{\mathrm{GEO}} \leq 0$ & Sinıf 1 & Kirli değil \\
$0<\mathrm{I}_{\mathrm{GEO}}<1$ & Sinıf 2 & Orta derecede kirli \\
$1<\mathrm{I}_{\mathrm{GEO}}<2$ & Sinıf 3 & Orta-kirli aras kirli \\
$2<\mathrm{I}_{\mathrm{GEO}}<3$ & Sinıf 4 & Yoğun kirli \\
$3<\mathrm{I}_{\mathrm{GEO}}<4$ & Sinıf 5 & Yoğun-aşırı aras kirli \\
$4<\mathrm{I}_{\mathrm{GEO}}<5$ & Sinıf 6 & Aşırı kirli \\
$5>\mathrm{I}_{\mathrm{GEO}}$ & Sinıf 7 & Çok aşırı kirli \\
\hline
\end{tabular}

Potansiyel ekolojik risk değerlendirme indeksi, ağır metallerin sediment tabakası içerisindeki ekolojik risk derecesini ortaya koyan ve Hakanson, (1980) tarafindan ortaya konulan bir yöntemdir. Yöntemin esası aşıda belirtilen formül $(5,6,7)$ ve sinıflandırmaya (Tablo 3) göre değerlendirilmektedir.

$$
\begin{aligned}
& \mathrm{C}_{\mathrm{f}}^{\mathrm{i}}=\mathrm{C}_{\mathrm{D}}^{\mathrm{i}} / \mathrm{C}_{\mathrm{R}}^{\mathrm{i}} \\
& \mathrm{E}_{\mathrm{r}}^{\mathrm{i}}=\mathrm{T}_{\mathrm{r}}^{\mathrm{i}} \times \mathrm{C}_{\mathrm{f}}^{\mathrm{i}} \\
& \mathrm{RI}=\sum_{\mathrm{i}=1}^{\mathrm{m}} \mathrm{E}_{\mathrm{r}}^{\mathrm{i}}
\end{aligned}
$$

Yukarıda verilen formülde RI; toplam bireysel ağır metal risk, $\mathrm{E}_{\mathrm{r}}^{\mathrm{i}}$; bireysel ağır metal risk, $\mathrm{T}_{\mathrm{r}}^{\mathrm{i}}$; ağır metal toksisite faktörü, $\mathrm{C}_{\mathrm{f}}$; ; kontaminasyon faktörü, $\mathrm{C}_{\mathrm{D}}{ }^{\mathrm{i}}$; çalışmada ölçülen metal konsantrasyonu olarak tanımlanmaktadır.

Tablo 3. Metal konsantrasyonunun ekolojik risk indeksine göre siniflandirilması

\begin{tabular}{lccc}
\hline $\mathbf{E}_{\mathbf{r}}{ }^{\mathbf{i}}$ & $\begin{array}{c}\text { Ekolojik metal } \\
\text { değerlendirme } \\
\text { riski (Bireysel) }\end{array}$ & RI & $\begin{array}{c}\text { Toplam potansiyel } \\
\text { ekolojik risk } \\
\text { değerlendirme }\end{array}$ \\
\hline $\mathrm{E}_{\mathrm{r}}{ }^{\mathrm{i}}<40$ & Düşük risk & $\mathrm{RI}<150$ & Düşük risk \\
$40 \leq \mathrm{E}_{\mathrm{r}}{ }^{i}<80$ & Orta risk & $150 \leq \mathrm{RI}<300$ & Orta risk \\
$80 \leq \mathrm{E}_{\mathrm{r}}{ }^{i}<160$ & Önemli risk & $300 \leq \mathrm{RI}<600$ & Önemli risk \\
$160 \leq \mathrm{E}_{\mathrm{r}}{ }^{\mathrm{i}}<320$ & Yüksek risk & $\mathrm{RI} \geq 600$ & Çok yüksek risk \\
$\mathrm{E}_{\mathrm{r}}{ }^{\mathrm{i}} \geq 320$ & Çok yüksek risk & & \\
\hline
\end{tabular}

Istatistiksel Analizler: Çalışmada, alansal ve zamansal farklılığı belirlemek amaciyla yapılan analizlerde sonuçların normal (Kolmogorov-Smirnov K-S testi) ve homojen dağılım (One Way Anova Homojenize testi) göstermesi sebebiyle tek yönlü varyans analizi (Tukey testi) uygulanmıştır (George ve Mallery, 2003). İstatistiki testlerin uygulanmasında SPSS 23.0 paket programı kullanılmıştır.

\section{BULGULAR ve TARTIŞMA}

Çalışma Alanına ait Fizikokimyasal Parametreler: Sediment ve su ortamında bulunan metallerin çözünürlüğü, dinamiği ve biyolojik olarak kullanıma hazır olma özelliği ile direkt olarak ilgili olan fiziksel ve kimyasal faktörlerin mevsimsel değerleri Tablo 4 ve Tablo 5'de gösterilmiştir. Metaller sedimentlerin ince tane boyu fraksiyonlarında birikme eğilimi gösterirler. İnce tane boyutundaki sedimenter partiküller geniş, spesifik yüzey alanına sahiptir ayrıca ince taneli sedimentlerin organik karbon içeriği yüksektir. Metal kirliliği ile ilgili çalışmalarda kirlenmiş yüzeylerin bir belirleyicisi olarak kil+silt boyutundaki fraksiyonlarda çalışılması tavsiye edilmektedir (Boldrin vd., 1989; Özşeker vd., 2014). Bu kapsamda yapılan çalışmada metal değerleri sedimentin kil+silt boyu fraksiyonunda değerlendirilmiştir. Göl ekosistemlerinde, metal değerleriyle direkt ilgili olan kil boyutu, en yüksek sonbahar mevsiminde Deriner Baraj Gölü'nde (\% 46) tespit edilmiştir. Dere ekosistemlerinde ise en yüksek kil miktarının sonbahar mevsiminde Murgul ve Deviskel Derelerinde (\%15) olduğu ortaya konulmuştur. Ayrıca kimyasal faktörler sedimentlerde bulunan metallerin çözünürlüğü, hareketliliği ve biyolojik olarak kullanıma hazır olabilme özelliği ile ilgili faktörlerdir (Förstner vd., 1989). Göl sularında oksijen derişimlerinin 6,14-7,18 mg/L arasında, toplam çözünmüş katı madde değerlerinin 157-341 $\mathrm{mg} / \mathrm{L}$ arasında ve $\mathrm{pH}$ değerlerinin 8,11-9,17 arasında değişim gösterdiği gözlemlenmiştir (Tablo 4). Dere sularının bu değerler oksijen için 9,54-13,01 mg/L, toplam çözünmüş katı madde için 104-194 mg/L ve $\mathrm{pH}$ için 8.10-8.41 değerleri

\begin{tabular}{|c|c|c|c|c|c|c|c|}
\hline Mevsim & $\begin{array}{l}\text { Bölge } \\
\text { (Göl) }\end{array}$ & $\begin{array}{l}\text { Kil+Silt } \\
(\%)\end{array}$ & $\begin{array}{l}\text { Kum } \\
(\%)\end{array}$ & $\begin{array}{l}\text { Çakıl } \\
(\%)\end{array}$ & $\begin{array}{l}\text { Oksijen } \\
(\mathrm{mg} / \mathrm{L})\end{array}$ & $\begin{array}{l}\text { TDS } \\
(\mathrm{mg} / \mathrm{L})\end{array}$ & $\mathrm{pH}$ \\
\hline \multirow{3}{*}{ İlkbahar } & Muratlı & $38 \pm 3,42$ & $55 \pm 3,84$ & $7 \pm 1,66$ & $6,87 \pm 0,32$ & $161 \pm 65,41$ & $8,50 \pm 0,68$ \\
\hline & Borçka & $41 \pm 2,71$ & $55 \pm 3,68$ & $4 \pm 1,84$ & $7,18 \pm 0,28$ & $157 \pm 44,17$ & $8,65 \pm 0,35$ \\
\hline & Deriner & $43 \pm 3,68$ & $49 \pm 3,20$ & $8 \pm 1,98$ & $6,95 \pm 0,36$ & $174 \pm 68,71$ & $8,63 \pm 0,30$ \\
\hline \multirow{3}{*}{ Yaz } & Muratlı & $36 \pm 2,96$ & $56 \pm 4,51$ & $8 \pm 1,90$ & $6,23 \pm 0,38$ & $245 \pm 54,23$ & $8,70 \pm 0,48$ \\
\hline & Borçka & $38 \pm 3,40$ & $57 \pm 3,70$ & $5 \pm 1,20$ & $6,14 \pm 0,38$ & $223 \pm 68,20$ & $9,10 \pm 0,52$ \\
\hline & Deriner & $38 \pm 3,28$ & $55 \pm 5,69$ & $7 \pm 1,45$ & $6,65 \pm 0,24$ & $261 \pm 66,40$ & $9,17 \pm 0,44$ \\
\hline \multirow{3}{*}{ Sonbahar } & Muratlı & $40 \pm 4,14$ & $53 \pm 4,45$ & $7 \pm 2,14$ & $6,90 \pm 0,26$ & $341 \pm 42,37$ & $8,43 \pm 0,35$ \\
\hline & Borçka & $42 \pm 3,71$ & $49 \pm 3,78$ & $9 \pm 2,42$ & $6,98 \pm 0,25$ & $333 \pm 38,56$ & $8,24 \pm 0,37$ \\
\hline & Deriner & $45 \pm 5,20$ & $46 \pm 6,25$ & $9 \pm 1,86$ & $7,11 \pm 0,31$ & $327 \pm 54,23$ & $8,32 \pm 0,51$ \\
\hline \multirow{3}{*}{ Kış } & Muratlı & $37 \pm 4,15$ & $54 \pm 3,80$ & $9 \pm 1,80$ & $6,33 \pm 0,33$ & $280 \pm 29,52$ & $8,20 \pm 0,46$ \\
\hline & Borçka & $37 \pm 3,47$ & $56 \pm 3,40$ & $7 \pm 1,40$ & $6,17 \pm 0,39$ & $214 \pm 38,74$ & $8,11 \pm 0,40$ \\
\hline & Deriner & $39 \pm 3,86$ & $58 \pm 4,20$ & $3 \pm 0,80$ & $6,71 \pm 0,41$ & $301 \pm 40,41$ & $8,14 \pm 0,32$ \\
\hline
\end{tabular}
arasında değişim göstermektedir (Tablo 5).

Tablo 4. Göllerde sediment ve yüzey sularına ait fizikokimyasal özelliklerin alansal ve mevsimsel dağılımı. 
$\underline{\text { Tablo 5. Derelerde sediment ve yüzey sularına ait fizikokimyasal özelliklerin alansal ve mevsimsel dağılımı. }}$

\begin{tabular}{clllllll}
\hline \multirow{2}{*}{ Mevsim } & $\begin{array}{l}\text { Bölge } \\
\text { (Dere) }\end{array}$ & $\begin{array}{l}\text { Kil + Silt } \\
(\%)\end{array}$ & $\begin{array}{l}\text { Kum } \\
(\%)\end{array}$ & $\begin{array}{l}\text { Çakıl } \\
(\%)\end{array}$ & $\begin{array}{l}\text { Oksijen } \\
(\mathrm{mg} / \mathrm{L})\end{array}$ & $\begin{array}{l}\text { TDS } \\
(\mathrm{mg} / \mathrm{L})\end{array}$ & $\mathrm{pH}$ \\
\hline \multirow{3}{*}{ Illkbahar } & Murgul & $12 \pm 1,80$ & $60 \pm 4,05$ & $28 \pm 2,31$ & $11,17 \pm 0,45$ & $112 \pm 30,41$ & $8,26 \pm 0,10$ \\
& Deviskel & $8 \pm 1,20$ & $61 \pm 4,22$ & $31 \pm 3,90$ & $12,10 \pm 0,87$ & $104 \pm 25,47$ & $8,31 \pm 0,05$ \\
& Ardanuç & $10 \pm 1,34$ & $56 \pm 3,78$ & $34 \pm 3,85$ & $11,451,20$ & $115 \pm 32,11$ & $8,15 \pm 0,08$ \\
\hline \multirow{3}{*}{ Yaz } & Murgul & $10 \pm 1,27$ & $58 \pm 2,21$ & $32 \pm 2,64$ & $10,01 \pm 0,41$ & $198 \pm 34,80$ & $8,39 \pm 0,12$ \\
& Deviskel & $14 \pm 0,58$ & $62 \pm 4,11$ & $24 \pm 2,10$ & $9,54 \pm 0,56$ & $176 \pm 33,21$ & $8,41 \pm 0,31$ \\
& Ardanuç & $11 \pm 1,30$ & $60 \pm 3,70$ & $29 \pm 3,47$ & $9,74 \pm 0,78$ & $184 \pm 28,20$ & $8,38 \pm 0,24$ \\
\hline \multirow{3}{*}{ Sonbahar } & Murgul & $15 \pm 2,45$ & $50 \pm 3,11$ & $35 \pm 1,87$ & $10,08 \pm 1,24$ & $181 \pm 26,32$ & $8,30 \pm 0,16$ \\
& Deviskel & $15 \pm 2,41$ & $52 \pm 2,58$ & $33 \pm 3,11$ & $10,54 \pm 1,31$ & $186 \pm 33,84$ & $8,31 \pm 0,11$ \\
& Ardanuç & $12 \pm 1,80$ & $50 \pm 4,06$ & $38 \pm 3,08$ & $10,24 \pm 0,55$ & $194 \pm 35,61$ & $8,34 \pm 0,21$ \\
\hline \multirow{3}{*}{ Kiş } & Murgul & $9 \pm 0,52$ & $57 \pm 4,25$ & $34 \pm 1,54$ & $12,49 \pm 1,11$ & $141 \pm 20,35$ & $8,14 \pm 0,08$ \\
& Deviskel & $11 \pm 0,87$ & $55 \pm 3,10$ & $34 \pm 1,98$ & $12,67 \pm 1,32$ & $127 \pm 25,12$ & $8,10 \pm 0,40$ \\
& Ardanuç & $8 \pm 1,05$ & $55 \pm 3,22$ & $37 \pm 2,74$ & $13,01 \pm 0,74$ & $151 \pm 30,10$ & $8,17 \pm 0,34$ \\
\hline
\end{tabular}

\section{Metal Derișimlerinin İrdelenmesi ve İstatistiksel} Analizler: Çalışma alanına ait metal derişimlerinin $(\mathrm{Cu}, \mathrm{Pb})$ alansal ve zamansal değişimleri Şekil 2 ve Şekil 3'de detaylı olarak sunulmuştur. Çalışma alanı göl ve bu gölleri besleyen dereler olmak üzere iki alt kategoride irdelendiğinde, göl ekosistemleri için; Muratlı Baraj Gölü'nde $\mathrm{Cu}$ elementi mevsimsel olarak 325,11 ile 361,91 ppm arasında değişim gösterirken, $\mathrm{Pb}$ elementinin mevsimsel değerleri ise 129,99 ile 176,84 ppm arasında değişim göstermektedir. Borçka Baraj Gölü'nde mevsimsel metal değerleri $\mathrm{Cu}$ elementi için 362,12 ile 563,67 ppm aralığında değişim göstermekle birlikte, $\mathrm{Pb}$ elementi için bu değerler 135,57 ile 179,30 ppm aralığında tespit edilmiştir. Deriner Baraj Gölü'nde ise $\mathrm{Cu}$ elementi değerleri 309,56 ile 381,23 ppm aralığında belirlenmişken, $\mathrm{Pb}$ elementi 129,74 ile 153,75 ppm aralığında gözlemlenmiştir (Şekil 2).

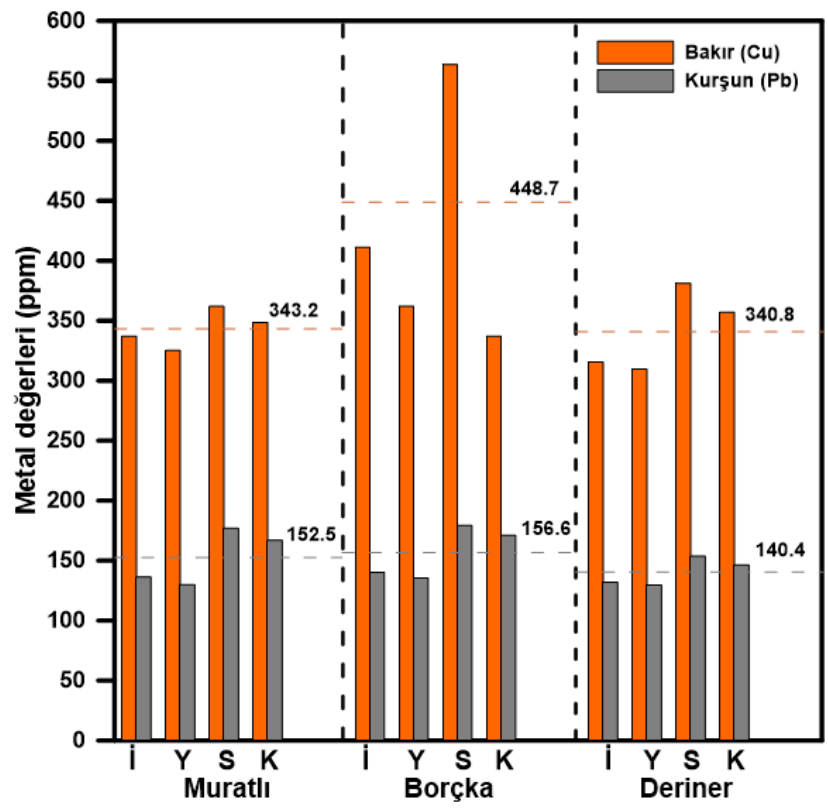

Şekil 2. Göl ekosistemleri için ortalama mevsimsel metal değerleri.

Dere ekosistemleri için; Murgul Deresi'nde $\mathrm{Cu}$ elementi mevsimsel olarak 592,50 ile 801,30 ppm arasında değişim gösterirken $\mathrm{Pb}$ elementinin mevsimsel değişimi ise 155,76 ile 192,78 ppm aralığında belirlenmiştir. Deviskel
Deresi için $\mathrm{Cu}$ elementi değerleri 322,70 ile 359,40 ppm aralığında tespit edilmişken $\mathrm{Pb}$ elementin mevsimsel değişimleri 124,80 ile $171,93 \mathrm{ppm}$ aralığında tespit edilmiştir. Ardanuç Deresi'nde ise $\mathrm{Cu}$ elementi 349,22 ile 484,99 ppm arasında gözlemlenmişken $\mathrm{Pb}$ elementin mevsimsel değişimi 131,53 ile 176,59 ppm aralığında bulunmuştur (Şekil 3).

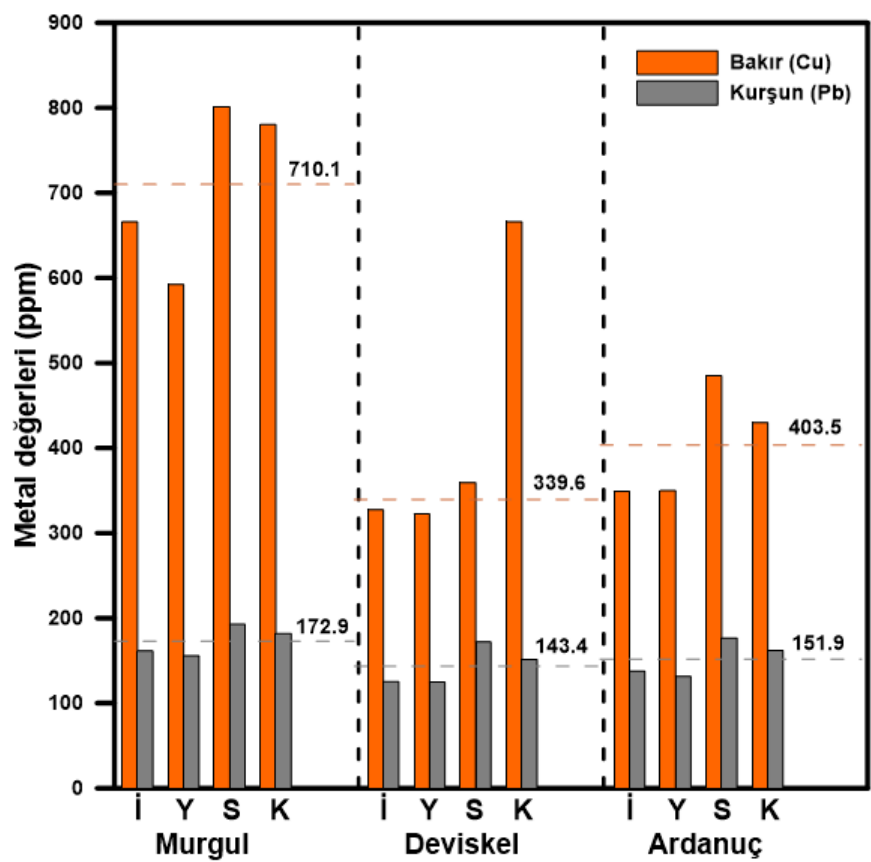

Şekil 3. Dere ekosistemleri için ortalama mevsimsel metal değerleri.

$\mathrm{Bu}$ çalışmada, iki bağımsız faktörün (araştırma bölgesi ve örnekleme dönemi) bağımlı değişken (metal derişimi) üzerine ortak etkisini ölçmek için iki yönlü anova (varyans) analiz istatistik testi kullanılmıştır. Bu testi kullanmamızdaki asıl amacımız faktörler arasındaki etkileşimin ortak etkisini incelemektir. Metal değerini bağımlı bileşen olarak irdelediğimizde, $\mathrm{Cu}$ elementi için bölge ekosistemi değişkenleri arasında $(\mathrm{F}=6,713 ; \mathrm{P}<0,05)$, dere ekosistemi değişkenleri arasında $(\mathrm{F}=108,024 ; \mathrm{P}<0,05)$ ve her iki ekosistem değişkeni arasında ise $(\mathrm{F}=241,324$; $\mathrm{P}<0,05)$ anlamlı bir fark görülmüş̧ür. $\mathrm{Pb}$ elementi için bölge ekosistemi değişkenleri arasında $(\mathrm{F}=45,699 ; \mathrm{P}<0,05)$, dere 
ekosistemi değişkenleri arasında $(\mathrm{F}=7,014 ; \mathrm{P}<0,05)$ ve her iki ekosistem değişkeni arasında ise $(\mathrm{F}=84,122 ; \mathrm{P}<0,05)$ anlamlı bir fark görülmüştür. $\mathrm{Bu}$ anlamlı farkın oluşmasındaki ana bileşenler ise göl ekosistemlerinde Borçka Baraj Gölü, dere ekosistemleri içerisinde ise Murgul Deresi'nden kaynaklandığı dikkat çekmektedir.

Metal Derişimlerinin Kirlilik ve Kalite Indekslerine

Göre Değerlendirilmesi: Yapılan çalışmada araştırma sahasına ait metal derişimlerinin yıllık ortalama değerleri Tablo 6'da sunulmuştur. Sunulan değerler dünya literatüründe kabul görmüş referans değerleri ile karşılaştırıldığında çalışmada elde edilen değerlerin yüksek olduğu dikkat çekmektedir. Kirlilik çalışmalarında önemli ölçüde dikkate alınan sediment kalite rehberi kriterleri ile karşılaştırma yaptığımızda ise $\mathrm{Cu}$ derişiminin Muratlı, Deriner Baraj Göllerinde ve Deviskel Deresi'nde ERM (Medyan Etki Eşiği) değerinden düşük olduğu fakat Borçka Baraj Gölü'nde, Murgul ve Ardanuç Derelerinde ise ERM değerinden yüksek olduğu sonucuna varmaktayız. Bunun haricinde $\mathrm{Cu}$ konsantrasyonu çalışma alanının tamamında PEL (Önerilen Etki Seviyesi), SEL (Yüksek Etki Seviyesi) ve TET (Toksik Etki Seviyesi) gibi kalite kriterlerinin tamamından yüksek bulunmuştur (Tablo 6). $\mathrm{Pb}$ elementinin ise ERM ve PEL değerlerinden yüksek olduğu SEL ve TET değerlerinden ise düşük olduğu görülmüştür.

Tablo 6. Çalışmada sunulan metal derişimleri ve referans değerleri ile karşılaştırılması

\begin{tabular}{|c|c|c|c|c|c|c|c|}
\hline \multicolumn{4}{|c|}{ Göl yüzey sedimenti ortalama yılllı değer } & \multicolumn{4}{|c|}{ Dere yüzey sediment ortalama yıllık değer } \\
\hline Metal & Muratlı & Borçka & Deriner & Murgul & Deviskel & \multicolumn{2}{|c|}{ Ardanuç } \\
\hline $\mathrm{Cu}$ & $343,2 \pm 15.6$ & $448,7 \pm 77.8$ & $340,8 \pm 32.1$ & $710,1 \pm 95.2$ & $339,6 \pm 18.1$ & \multicolumn{2}{|c|}{$403,5 \pm 60.6$} \\
\hline $\mathrm{Pb}$ & $152,5 \pm 20.9$ & $156,6 \pm 20.0$ & $140,5 \pm 11.2$ & $172,9 \pm 19.6$ & $143,4 \pm 20.7$ & \multicolumn{2}{|c|}{$151,9 \pm 19.5$} \\
\hline \multicolumn{8}{|c|}{ Referans Değerleri } \\
\hline & & & & \multicolumn{4}{|c|}{$\mathrm{SOQ}^{\mathrm{a}}$} \\
\hline Metal & WASV $^{\mathrm{b}}$ & $\mathrm{CCV}^{\mathrm{c}}$ & $\mathrm{TRV}^{\mathrm{d}}$ & ERM & PEL & SEL & TET \\
\hline $\mathrm{Cu}$ & 45 & 55 & 16 & 390 & 197 & 110 & 86 \\
\hline $\mathrm{Pb}$ & 20 & 12.2 & 31 & 110 & 91.3 & 250 & 170 \\
\hline
\end{tabular}

Tatlı su ekosistemlerinde kimyasalların biyolojik ortamdaki önemini belirlemek için kullanılan önemli bir karşılaştırma rehberi olan sediment kalite rehberi (SGV) metallerin ekolojik riskinin değerlendirilmesinde kullanılan yaygın kıyaslama yöntemlerinden biridir. Çalışma sahasından elde edilen veriler aşağıda belirtilen Tablo 7'ye göre değerlendirilmiştir (US EPA., 1999). Çalışma alanından elde ettiğimiz sonuçları tatlı su ekosistemleri için hazırlanmış sediment kalite rehberi kriterlerine göre değerlendirdiğimizde $\mathrm{Cu}$ ve $\mathrm{Pb}$ elementlerinin çalışma alanının tümü için sınıf 3 (yoğun kirli) kategoride tespit edilmiştir.

Tablo7. Sediment kirlilik rehberine göre metal konsantrasyonlarının siniflandırilmasi.

\begin{tabular}{llll}
\hline & \multicolumn{3}{l}{ Sediment Kirlilik Rehberine (SGV) Göre Kriter Değerleri } \\
\hline Metal limitleri & Kirlenmemiş (Sınıf 1) & Orta Kirli (Sınıf 2) & Yoğun Kirli (Sınıf 3) \\
\hline $\mathrm{Cu}$ & $<32$ & $32-150$ & $>150$ \\
$\mathrm{~Pb}$ & $<36$ & $36-130$ & $>130$ \\
\hline
\end{tabular}

Metal derişimlerinin araştırma sahası için kirlilik unsuru oluşturup oluşturmadığını irdelemek amacıyla çalışma alanından elde ettiğimiz veriler dünya çapında yaygın olarak kullanılan kirlilik indekslerine göre detaylıca değerlendirilmiştir (Tablo 8).Çalışma alanına ait metal derişimleri sediment zenginleşme faktörüne (SEF) göre değerlendirildiğinde sonuçların $\mathrm{SEF}>1,5$ olduğu dikkat çekmektedir. $\mathrm{SEF}>1,5$ ise araştırma sahasındaki metal kontaminasyonun kaynağı antropojenik olarak değerlendirilebilir (Xiao vd., 2014). Cu ve Pb elementleri için en yüksek SEF değerleri göl ekosistemleri içerisinde Borçka
Baraj Gölü'nde sonbahar mevsiminde 10,4-5,8; dere ekosistemleri içerisinde Murgul Deresi'nde 10,9-6,4 olarak tespit edilmiştir.

Muller (1981) tarafindan ortaya konulan ve sediment tabakasında ağır metal konsantrasyonu üzerinde antropojenik etkinin derecesini belirlemek amaciyla kullanılan jeoakümülasyon indeksine göre kirlilik derecesi 7 farklı kategoride değerlendirilmektedir (Tablo 2). Elde ettiğimiz değerler bu yönteme göre değerlendirildiğinde $\mathrm{Cu}$ elementi için Borçka Baraj Gölü ve Murgul Deresi verileri $3<\mathrm{I}_{\mathrm{GEO}}<4$ (kategori 4 ) aralığında belirlendiği için yoğun-aşırı arası kirlilik sınıfında kategorize edilmiştir. Diğer bölgeler için sonuçlar $2<\mathrm{I}_{\mathrm{GEO}}<3$ (kategori 3) aralığında belirlenmiş olup yoğun kirli sınıfında kategorize edilmişlerdir. Çalışma sahasının tümünde ise $\mathrm{Pb}$ elementi $2<\mathrm{I}_{\mathrm{GEO}}<3$ (kategori 3 ) aralığında tespit edildiğinden yoğun kirli kategori altında değerlendirilmiştir.

Hakanson (1980) tarafindan ortaya konulan, ağır metallerin sediment tabakası içerisindeki ekolojik risk derecesini değerlendiren potansiyel ekolojik risk değerlendirme indeksine (RI) göre metal kontaminansyonu risk faktörü dört ayrı sınıfta kategorize edilmiştir. Çalışmadan elde edilen sonuçlar bu yönteme göre değerlendirildiğinde diğer yöntemlerle benzer olarak Borçka Baraj Gölü'nde, Murgul ve Ardanuç Derelerinde Cu elementi için RI değerleri $150 \leq \mathrm{RI}<300$ aralığında tespit edildiğinden dolayı orta risk sınıfında değerlendirilmiştir. Çalışma alanının tümü için $\mathrm{Pb}$ elementi $\mathrm{RI}$ değerleri $\mathrm{RI}<150$ olarak hesaplandığı için düşük risk sınıfında değerlendirilmiştir. 
Çevredeki metal kirliliğinin şiddetini değerlendiren ve etkili bir yöntem olan kirlilik yük indeksi (PLI)'ye göre ise sonuçlar tüm çalışma alanında PLI $>1$ olarak tespit edildiğinden çalışılan alanda kirliliğin mevcut olduğu sonucu ortaya konulmuştur. Yukarıda belirtilen indekslerle benzerlik göstererek en şiddetli kirliliğe maruz kalan bölgeler Borçka Baraj Gölü ve Murgul Deresi olarak tespit edilmiştir.

Tablo 8. Metal değerlerinin kirlilik indekslerine göre değerlendirilmesi

\begin{tabular}{|c|c|c|c|c|c|c|c|c|c|c|c|c|c|c|c|}
\hline & Metal & SEF $^{1}$ & $\mathrm{SEF}^{2}$ & SEF $^{3}$ & SEF $^{4}$ & $\mathbf{I}_{\text {GEO }}{ }^{1}$ & $\mathbf{I}_{\mathrm{GEO}^{2}}$ & $\mathbf{I}_{\mathrm{GEO}}{ }^{3}$ & $\mathbf{I}_{\mathrm{GEO}}{ }^{4}$ & $E_{R}{ }^{1}$ & $\mathbf{E}_{\mathrm{R}}{ }^{2}$ & $\mathbf{E}_{\mathrm{R}}{ }^{3}$ & $E_{R}{ }^{4}$ & RI & PLI \\
\hline \multirow{2}{*}{ Muratlı } & $\mathrm{Cu}$ & 6,2 & 6,1 & 6,7 & 6,5 & 2,32 & 2,26 & 2,42 & 2,36 & 33,7 & 32,5 & 36,2 & 34,9 & 137,2 & 6,8 \\
\hline & $\mathrm{Pb}$ & 5,7 & 5,4 & 7,3 & 6,9 & 2,18 & 2,11 & 2,55 & 2,47 & 9,7 & 9,3 & 12,6 & 11,9 & 43,5 & 2,1 \\
\hline \multirow{2}{*}{ Borçka } & $\mathrm{Cu}$ & 7,6 & 6,7 & 10,4 & 8,5 & 2,60 & 2,42 & 3,06 & 2,76 & 41,1 & 36,2 & 56,4 & 45,7 & 179,5 & 8,8 \\
\hline & $\mathrm{Pb}$ & 5,8 & 5,6 & 7,4 & 7,1 & 2,25 & 2,17 & 2,57 & 2,51 & 10,0 & 9,6 & 12,8 & 12,2 & 44,7 & 2,2 \\
\hline \multirow{2}{*}{ Deriner } & $\mathrm{Cu}$ & 5,8 & 5,7 & 7,1 & 6,6 & 2,22 & 2,19 & 2,49 & 2,40 & 31,5 & 30,9 & 38,1 & 35,7 & 136,3 & 6,7 \\
\hline & $\mathrm{Pb}$ & 5,4 & 5,4 & 6,4 & 6,1 & 2,13 & 2,11 & 2,35 & 2,28 & 9,4 & 9,3 & 10,9 & 10,5 & 40,1 & 2,0 \\
\hline \multirow{2}{*}{ Murgul } & $\mathrm{Cu}$ & 12,3 & 10,9 & 14,8 & 14,4 & 3,30 & 3,13 & 3,57 & 3,53 & 66,5 & 59,2 & 80,1 & 78,0 & 284,0 & 14,0 \\
\hline & $\mathrm{Pb}$ & 6,7 & 6,4 & 8,0 & 7,5 & 2,42 & 2,37 & 2,68 & 2,60 & 11,5 & 11,1 & 13,7 & 34,9 & 49,5 & 2,4 \\
\hline \multirow{2}{*}{ Deviskel } & $\mathrm{Cu}$ & 6,0 & 5,9 & 6,6 & 6,4 & 2,27 & 2,25 & 2,41 & 2,37 & 32,7 & 32,2 & 35,9 & 34,8 & 135,8 & 6,7 \\
\hline & $\mathrm{Pb}$ & 5,2 & 5,2 & 7,1 & 6,3 & 2,06 & 2,05 & 2,51 & 2,33 & 8,9 & 8,9 & 12,2 & 10,8 & 40,9 & 2,0 \\
\hline \multirow{2}{*}{ Ardanuç } & $\mathrm{Cu}$ & 6,4 & 6,4 & 8,9 & 7,9 & 2,37 & 2,37 & 2,84 & 2,67 & 34,9 & 34,9 & 48,4 & 42,9 & 161,4 & 7,9 \\
\hline & $\mathrm{Pb}$ & 5,7 & 5,4 & 7,3 & 6,7 & 2,19 & 2,13 & 2,55 & 2,43 & 9,8 & 9,4 & 12,6 & 11,5 & 43,4 & 2,1 \\
\hline
\end{tabular}

Artvin İli tatlı su ekosistem sedimentleri ve dolayıs1 ile bu ekosistemlerde kirlilik üzerine yapılan çalışmalara ait veriler göl ve bu gölleri besleyen dere ekosistemleri olmak üzere ayrı ayrı değerlendirilmişlerdir. En yüksek metal derişimleri ve dolayısı ile çevresel kirlilik etkileri Borçka Baraj Gölü ve Murgul Deresi'nde gözlenmiştir. Araştırma bölgeleri kirlik açısından sıralamaya tabi tutulduklarında $\mathrm{Cu}$ elementi için en yüksek değerler Murgul Deresi>Borçka Baraj Gölü $>$ Ardanuç Deresi $>$ Muratlı Baraj Gölü $>$ Deriner Baraj Gölü $>$ Deviskel Deresi şeklindedir. Pb elementi için ise sıralama Murgul Deresi $>$ Borçka Baraj Gölü $>$ Muratlı Baraj Gölü>Ardanuç Deresi>Deviskel Deresi>Deriner Baraj Gölü olarak görülmektedir. Çalışma alanına ait elde edilen veriler mevsimsel olarak irdelendiğinde ise en yüksek değerler sonbahar $>\mathrm{k}$ ış $>\mathrm{ilkbahar}>\mathrm{yaz}$ sıralamasında tespit edilmiştir. $63 \mu \mathrm{m}$ 'den küçük tane boyutundaki malzeme fraksiyonları doğal ve antropojenik bileşenlerin en etkili taşıyıcısı olduklarından ağır metal içerikleri kil+silt boyutlu malzeme içeriği üzerinden değerlendirilmiştir. Ayrıca kil boyutundaki malzeme fraksiyonu uzun mesafeler boyunca taşınabilmesi özelliği ile kirlilik çalışmalarında ayrıca önem teşkil etmektedir.

$\mathrm{Bu}$ çalışmada en yüksek metal değerleri kil boyutlu malzeme fraksiyonlarının birikim yaptı $\breve{1}$ istasyonlarda gözlenmiştir. Bu çalışmada elde edilen sonuçlar aynı bölgede yapılan diğer çalışmaların bulguları ile karşılaştıııldığında (Turgut vd., 2015; Özşeker, 2019), sonuçların benzer olduğu ve çalışılan parametreler açısından mevsim değerlerinin genel özelliklerini yansıttı̆̆ 1 görülmektedir. Ayrıca Gedik vd., 2018 tarafindan Borçka Baraj Gölü'nde yapılan bir çalışmada sediment, su kolunu ve bazı balık türlerinde metal derişimleri irdelenmiştir. Sediment tabakasında değerlendirdikleri $\mathrm{Cu}$ ve $\mathrm{Pb}$ derişimleri çalışmamızda sunulan değerlerle benzerlik göstermektedir. Toksik metal konsantrasyonu, $\mathrm{pH}$, tuzluluk, sicaklık ve redoks durumu gibi birçok faktöre bağlı olarak değişebilir. $\mathrm{Bu}$ faktörler meteoroloji ile ilgili abiotik faktörlerdir. Sonbaharda meteoroloji koşulları hızlı ve güçlü bir değişime neden olur. $\mathrm{Bu}$ durum yağmur ve buna bağlı yüksek erozyon rolü ile metal kontaminasyonunu sağlamaktadır. metalin kontamine olan havadaki tozunu gidermede yağmurun rolünü doğrular (Melaku vd., 2008). Bu sebeplerden dolayı sonbahar mevsiminde tespit ettiğimiz yüksek metal konsantrasyonları Artvin ilinin bu mevsimde çok yüksek miktarda yağış alması ve buna bağlı olarak maruz kaldığı yoğun erozyona bağlı olarak düşünülebilir.

\section{SONUÇ}

Günümüzde, su ortamının kalitesinin, doğal ve antropojenik kaynaklardan gelen farklı türdeki kirleticiler tarafından tehdit edildiği bilinmektedir. Borçka Baraj Gölü ve Murgul Deresi'ndeki yüksek kirlilik seviyeleri, yüksek doğal mineralojik yapının yanında bölgedeki antropojenik etkinin dikkate alınması gerektiği ortaya koymaktadır. Fakat bölgedeki doğal mineralojik yapı ne kadar yüksek olursa olsun kirliliğin ana nedeni antropojenik etki olarak düşünülmektedir. Bölgede aktif olarak işletilen bir bakır madeni mevcut durumda bulunmaktadır. Madenlerin çevresel etkileri göz önüne alındığında, madencilik alanında kullanılan atık suyun yüzey suyunun doğal özelliklerini değiştirdiği ve su ortamında çevreyi olumsuz yönde etkileyen farklı sediment tabakası oluşturduğu bilinmektedir.

Su madencilik faaliyeti yapılan bütün bölgelerde çok gerekli ve dolayısıyla çok gerekli olduğundan kapalı sisteme tabidir. Ancak su kaçaklarının olması kaçınılmazdır. Ayrıca mineral zenginleştirme işlemleri sonucunda kalıntı malzemenin bertaraf edilmesi de balçık halde olduğundan dolayı bir miktar su kaybı da bu aşamada söz konusudur. Antropojenik etkilere bağlı olarak, madencilik atık suları ve bakır cürufu, yağmur ve erozyon gibi çevresel koşullar nedeniyle bölgede yüksek düzeyde metal konsantrasyonuna 
neden olduğu için daha yüksek çevresel kirlilik seviyelerine neden olmaktadır.

Çalışma alanının çevresinin doğal mineralojik yapısının yüksek olmasının yanında, karayolu yapımı, baraj yapımı, taş kırma tesisleri, asfalt tesisleri, evsel ve endüstriyel atıkların direkt Çoruh nehri havzasına deşarj edilmesi gibi birçok antropojenik etki tatlı su ekosistemlerini çevreleyen kıta kesiminde yoğun olarak faaliyet göstermektedir. Bu çalışmanın sonuçlarına dayanarak, $\mathrm{Cu}$ ve $\mathrm{Pb}$ elementlerinin Artvin ili tatlı su ekosistemleri için toksik etki gösterdiği ve bu ekosistemlerin metal kirliliği açısından orta risk sınıfında değerlendirilmesi gerektiği sonucu ortaya konulmuştur.

Sucul ortamlardaki yüzey sedimentlerinin jeokimyası su kolonu kimyasını da etkiler sedimentlerde depolanan ağır metaller bu nedenle sadece bentik organizmalar üzerinde değil aynı zamanda su kolonundaki ekosistem üzerinde toksik bir etki oluşturur. Bu nedenlerden dolayı limnetik ekosistemlerde sediment tabakasındaki metal içeriğinin su kolonu ile birlikte incelenmesi bu ekosistemler için daha önemli sonuçlar ortaya koyacaktır.

\section{KAYNAKLAR}

Abraham, G.M.S. \& Parker, R.J. (2008). Assesment of heavy metal enrichment factors and the egree of contamination in marine sediments from Tamaki Estuary, Auckland, New Zelaland. Environmental Monitoring and Assessment, 227-238.

Anonim. (2015). Artvin ili taşkın ve rusubat kontrol faaliyetleri. T.C. Orman ve Su İşleri Bakanlığı, DSİ Çoruh Projeleri 26. Bölge Müdürlüğü, Artvin, Türkiye.

Anonim. (2010). MTA Doğu Karadeniz Bölge Müdürlüğü, Artvin İli Doğal Kaynaklar Envanteri, Trabzon, Türkiye.

Anonim. (2005). Artvin Valiliği İl Çevre ve Şehircilik Müdürlüğü. Artvin İl Çevre Durum Raporu, Artvin, Türkiye.

Aytekin, M. (2004). Deneysel Zemin Mekaniği. Teknik Yayınevi, Ankara, Türkiye.

Boldrin, A., Jurack, M., Menegazzo Vitturi, L., Rabitti, S. \& Rampzzo, G. (1989). Geochemical considerations on trace elements distributions in suspended matter and sediments at the river-sea inter face, Adige River Mouth, Northern Adriatic Sea. Applied Geochemistry, 4, 409-421.

Cevik, F., Ziya, M., Goksu, L., Deric, O.B. \& Fındık, O. (2009). An assesment of metal pollution in surface sediments of Seyhan Dam by using enrichment factor, geoaccumulation index and statical analyses. Environmental Monitoring and Assessment, 227238., 997-1009.
Dulski, P. (2001). Reference materials for geochemical studies: new analytical databy ICP-MS and critical discussion of reference values. Geostandards Newslett: The Journal of Geostandards and Geoanalysis, 25, 87-125.

Förstner, U. (1989). Lecture Notes in Earth Sciences, 21. Contamined sediments. 157 pp. Springer, Verlag.

Hakanson, L. (1980). An ecological risk index for aquatic pollution control, A sedimentological approach. Water Research, 14, 975-1001.

Gedik, K., Terzi, E. \& Yeşilçiçek, T. (2018). Biomonitoring of metal (oid)s in mining-affected Borcka Dam Lake coupled with public health out comes. Human and Ecological Risk Assessment, 63, 1-19.

George, D. \& Mallery, P. (2003). SPSS for windows step by step. A Simple Guide and Reference 15,0 Update, Furth Edition, Boston, 386.

Kurupadam, R.J., Simita, P. \& Wate, S.R. (2006). Geochemical fractionation of heavy metala in sediments of the Tapi estuary. Geochemical Journal, 40, 513-522.

MacDonald, D.D. \& Ingersoll, C.G. (2000). Development and evaluation of consensus-based sediment quality guidelines for freshwater ecosystems. Archives Environmental Contamination and Toxicology, 39, 20-31.

Melaku, S., Morris, V., Raghavan, D. \& Hosten, C. (2008). Seasonal variation of toxic metals in ambient air and precipitation at a single site in Washington. DC., Environmental Pollution, 155, 88-98.

Muller G. (1981). Die Schwer metall belstang der sedimentdes Neckararsundseiner N ebenflusseeineest and saufnahme. Chemical Zeitung, 105, 157-164.

Özşeker, K., Eruz, C., Cılız, S. \& Mani, F. (2014). Assessment of toxic metal contribution and associated ecological risk in the coastal zone sediments of Black Sea; Case study of Trabzon. CLEAN-Soil, Air, Water, 42, 1477-1482.

Özşeker, K. (2019). Investigation of sediment pore water heavy metal $(\mathrm{Cu}$ and $\mathrm{Pb})$ geochimistry in Deriner Dam Lake, Artvin, Turkey. Acta Aquatica Turcica, 15(1), 60-67.

Swarnalatha, K., Letha, J. \& Ayoob, S. (2013a). An investigation into the heavy metal burden of Akkulam-Veli Lake in South India. Environ Earth Sciences, 795-806.

Swarnalatha, K., Letha, J., Ayoob, S. \& Sheela, A.M. (2013b). Identification of $\mathrm{Si}$ as $\mathrm{An}$ appropriate normalizer for estimating the heavy metals enrichment of An Urban Lake System. Journal of Environmental Management, 175-192. 
US EPA, A. (2002). Guidance manual to support the assessment of contaminated sediments in freshwater ecosystems. Volume III-Interpretation of the Results of Sediment Quality Investigations. U.S. Environmental Protection Agency EPA-905-B02001-C, December.

Taş, B. (2011). Gaga Gölü (Ordu) su kalitesinin incelenmesi. Karadeniz Fen Bilimleri Dergisi, 1(3), 43-61.

Taylor, S.R. (1964). Abundances of chemical elements in the continental crust: A new table. Geochimica et Cosmochimica Acta, 28, 1273-1285.

Turekian, K.K., \& Wedephol, K.H. (1961). Distribution of the elements in some major units of the earth's crust. Geological Society American Bulletin, 72, 175-192.

Turgut, B., Ozalp, M. \& Kose, B. (2015). Physical and chemical properties of recently depositeds ediments in the reservoir of the Borçka Dam in Artvin, Turkey. Journal of Agricultural and Food Chemistry, 39, 663.
UNEP. 1995. United Nations Environment Programme, Environment for Devolopment. Nairobi, Kenya.

Xiao, H., Zang, S., Guan, Y., Liu, S., Gao, Y., Sun, Q., Xu, H., Li, M., Wang, J. \& Pei, X. (2014). Assesment of potantial risks associated with heavy metal contamination in sediment in Aobapao Lake, China, Determined from sediment cores. Ecotoxicology, 23, 527-537.

\section{*Corresponding author's:}

Koray ÖZŞEKER

Karadeniz Teknik Üniversitesi, Deniz Bilimleri ve Teknolojisi Enstitüsü, Trabzon, Türkiye.

\E-mail: ozseker.koray@gmail.com

ORCID : https://orcid.org/0000-0002-7044-1843

GSM : $+90(539) 3679773$ 